\title{
CATHERINE POZZI Y MARCELLE SAUVAGEOT: ESCRIBIR LA SOLEDAD DEL ALMA EN UN CUERPO DE ESCRITURA
}

\author{
Amelia Peral Crespo \\ Universidad de Alicante
}

\begin{abstract}
RESUMEN: La escritura de Catherine Pozzi y Marcelle Sauvageot está intimamente ligada a la soledad que ha determinado sus vidas. La relación existente entre la soledad y la escritura como refugio del ser y a su vez como impulso escritural no se puede separar de los conceptos de alma y cuerpo presentes sobre todo en la obra de Catherine Pozzi. ¿Cómo separar el alma del cuerpo, y el cuerpo del alma? se preguntaba Pozzi en Peau d'Âme. ¿No sería acaso como separar la escritura de la soledad que la alimenta? En sus obras, la soledad se construye en base a dos aspectos que tampoco pueden disociarse: la enfermedad, es decir la tuberculosis que las conduce irremediablemente hacia una muerte prematura, y la necesidad de escapar como mujeres a las normas sociales preestablecidas e impuestas por la sociedad en la que viven. La soledad existencial en la construcción del ser que se forja al hilo de sus palabras es uno de los fenómenos que impulsa la necesidad de expresarse mediante la escritura.

PALABRAS CLAVE: Cuerpo, alma, escritura de mujeres, soledad, Catherine Pozzi, Marcelle Sauvageot.
\end{abstract}

\section{CATHERINE POZZI ET MARCELLE SAUVAGEOT: ÉCRIRE LA SOLITUDE D'UNE ÂME DANS UN CORPS D'ÉCRITURE}

RÉSUMÉ: L'écriture chez Catherine Pozzi et Marcelle Sauvageot ne peut pas être séparée de la solitude qui a marqué leur vie. La relation existante entre la solitude et l'écriture comme refuge et élan est indissociable de la conception de l'âme et du corps présente surtout dans l'œuvre de Catherine Pozzi. Comment séparer l'âme du corps et le corps de l'âme? se demandait Pozzi dans Peau d'Âme. Comment séparer l'écriture de la solitude qui la nourrit? Dans leurs cuvres, la solitude se construit principalement sur deux aspects qui, eux aussi, ne peuvent pas être dissociés: la maladie, la tuberculose, qui les mène à une mort prématurée et le besoin d'échapper en tant que femmes aux normes sociales préétablies et imposées par l'époque. De ce fait, la solitude de vivre dans la 
construction de l'être, qui se forge au fil des mots, devient l'un des phénomènes qui déclenche le besoin de se dire en écriture.

MOTS CLES: Corps, âme, écriture de femmes, solitude, Catherine Pozzi, Marcelle Sauvageot.

\section{Introducción}

El tiempo transcurrido les ha dado la razón. Catherine Pozzi y Marcelle Sauvageot fueron dos mujeres que vivieron a caballo entre dos siglos marcados por grandes cambios ideológicos, políticos, sociales y literarios. En una época donde la femme-auteur ${ }^{1}$ era tildada de "femme à plume" (Aubaud 1993: 134), incluso de bas-bleue $^{2}$, las mujeres que escribieron se vieron casi obligadas a definirse no sólo ante el hombre sino también ante el feminismo ${ }^{3}$ de finales del XIX y comienzos del XX. En el contexto histórico del feminismo de la première vague ${ }^{4}$, las mujeres que, como George Sand, Rachilde, Flora Tristan entras otras muchas, consiguieron ser reconocidas como escritoras, dieron paso durante la primera mitad del siglo

1. Remitimos al estudio realizado por Christine Planté en La petite søur de Balzac, sobre la 'femmeauteur': «on ne parle pas d'homme auteur, ce qui veut dire qu'ici comme ailleurs le masculin et le neutre [...] se confondent. Pour se nommer et se définir dans son activité de créatrice, la femme qui écrit est donc obligée de se situer d'emblée comme être sexué, d'inscrire le fait d'être femme au cœur de son œuvre» (Planté 1989: 25).

2. En este sentido, distintos escritores franceses de finales del siglo XIX como, Barbey d'Aurevilly, han comparado de manera despectiva a las escritoras con des bas-bleues. Barbey d'Aurevilly concibió toda una revolución literaria basada en el bas-bleuisme.

3. El término feminismo se presta a varias y controvertidas definiciones como apunta Ute Gerhard (2004: 47). Atribuido en un principio a Charles Fourier, se ha demostrado que en 1872 Alexandre Dumas, hijo, lo empleaba desde un punto de vista peyorativo haciendo referencia a esos femmelins (Riot-Sarcey 2002: 5), a aquellos hombres que defendían la causa de las mujeres: «qui renoncent à leur virilité en prenant fait et cause pour les femmes en cas d'adultère» (Studer 2004: 23). Para un estudio histórico sobre el feminismo en Francia hasta mediados de los años 70, nos parece fundamental el estudio de Albistur, D. y Armogathe, M. (1997). Histoire du féminisme français. París: Des femmes.

4. Para Ute Gerhard: «cette métaphore de la vague est moins analytique que descriptive, mais elle caractérise parfaitement [...] le fait que les différents mouvements de protestation se nourrissent à la fois d'une même problématique et de nombreuses contradictions» (Gerhard 2004: 48). En este sentido y adoptando dicha terminología, la primera ola a la que hacemos referencia surge en la segunda mitad del siglo XIX y principios del XX, girando en torno al derecho al voto. Tradicionalmente y desde un punto de vista histórico, se han distinguido dos olas en los movimientos feministas: la primera ya mencionada y una segunda denominada 'neofeminismo' que abarcaría el periodo de mediados de los años 1960 y principios de 1970. Desde 1990, se viene haciendo referencia a «une troisième vague, globale ou transnationale» (Gerhard 2004: 48). 
XX a escritoras como Colette, Anna de Noailles ${ }^{5}$, Renée Vivien, Elsa Triolet, Marie de Régnier ${ }^{6}$, Anaïs Nin... que, entre 1900 y 1920, época en la que vivieron Catherine Pozzi y Marcelle Sauvageot: hicieron del eterno femenino un problema de actualidad (Albistur-Armogathe 1977: 586). El eterno femenino de principios del siglo XX retoma de nuevo, basado en una concepción dualista, los temas de la mujer ángel y la mujer demonio, temas tan recurrentes en la literatura de la segunda mitad del XIX. La mujer encuentra un reflejo de estos estereotipos en la «femmeenfant et son contraire la garçonne ${ }^{7} \gg$ (Albistur-Armogathe 1977: 586). Y cómo no mencionar a Valentine de Saint-Point que, en 1912, publicó Le manifeste de la femme futuriste como respuesta al manifiesto futurista de Marinetti de 1909 en el que proponía acabar con el feminismo entre otras muchas bajezas sociales.

La condición de 'femme auteur' de Catherine Pozzi y Marcelle Sauvageot difiere radicalmente de las escritoras mencionadas anteriormente, de estas «femmes d'encrier» ${ }^{8}$. Marcelle Sauvageot nunca se planteó ser escritora. De hecho, podemos afirmar que lo fue casi sin proponérselo. Sólo se le conoce un libro, fruto de un impulso escritural tan breve como intenso. Catherine Pozzi escribía. Además lo hacía desde su más tierna adolescencia. Mantuvo un diario hasta el final de su vida y una intensa correspondencia con escritores como Rilke ${ }^{9}$, entre otros. Hizo incursiones en otros géneros literarios pero, por encima de todo, no quería que su nombre figurase en sus libros, como veremos más adelante. Se resistía a compartir con un hipotético lector sus creaciones literarias. ¿Tal vez por temor o por pudor? No parece ser ésta la causa. Catherine Pozzi, la mujer que temía ver su nombre en la

5. Catherine Pozzi mantuvo con la escritora Anna de Noailles, tal y como se desprende de la lectura de su Diario, una relación un tanto peculiar, rozando en algunos casos el desprecio. Así el 23 de julio de 1924 escribe: «6 heures, Anna de Noailles. Elle dit qu'elle n'est comparable à aucune autre. Qu'aucune autre n'atteint à la beauté de ses joies et de ses douleurs. Qu'il lui faut la vie complète et intense. Que certaines personnes, d'ailleurs délicieuses... (merci, grotesque divine !) peuvent être contentes en ne respirant qu'à demi d'un seul poumon et vivre une vie diminuée dont elles ne s'aperçoivent même pas. Qu'à elle il faut tout!

Rarement entendu discours aussi peu intelligent et même... aussi odieux» (Pozzi 1987: 311-312). La prueba de que las palabras pronunciadas por Anna de Noailles consiguieron enfurecer a Pozzi también la tenemos una vez más en su diario. Catherine Pozzi retoma literalmente al día siguiente el desacertado comentario de Anna de Noailles: «Une vie diminuée dont je ne m’aperçois même pas...» (Pozzi 1987: 312).

6. Gran amiga de Catherine Pozzi.

7. En 1922, Victor Marguerite publicó La Garçonne. Fue un éxito y un escándalo a la vez en el París literario de principios del siglo pasado.

8. Retomamos el título del estudio realizado por Patricia Ferlin, Femmes d'encrier en 1995.

9. Catherine Pozzi mantuvo con Rainer Maria Rilke hasta la muerte de éste una intensa correspondencia. La admiración y el respeto entre ambos era mutuo. 
portada de sus libros, no huía de su escritura, huía ante todo de sí misma. Sometida a una fuerte disciplina, su nivel de autoexigencia fue muy alto, de ahí el temor a las críticas. La necesidad de encontrar en el otro un apoyo, «une troisième jambe» como dice Clarice Lispector (1998: 24) o una especie de muleta sobre la que apoyarse, se convierte para la escritora, a lo largo de su corta existencia, en la búsqueda de un otro idealizado. Esa imagen se romperá cuando el ser creado cobre vida, y la vida misma no sea más que un largo y penoso camino de espinas. La escritura ocupará el lugar de ese otro soñado, idealizado, imaginado y sobre todo tan irreal e inexistente como esa tercera pierna. Pero aun nos queda un largo camino por recorrer hasta llegar a ese instante en el que Pozzi y Sauvageot pudieron sentir todo el peso y dolor del respirar, a medias, porque como nos dice Clarice Lispector desde su concepción existencialista de la escritura: «C'est qu'un monde totalement vivant à la puissance d'un Enfer» (Lispector 1998: 37).

En un momento histórico, que no era propicio ni a su emancipación como mujeres ni como femmes de plume, estas dos escritoras vieron la luz. Catherine Pozzi nació a finales del siglo XIX ${ }^{10}$, en el seno de una familia burguesa parisina cuya notoriedad en los diversos salones literarios del momento le permitió codearse con los personajes ${ }^{11}$ más célebres del París de principios de siglo. Marcelle Sauvageot inauguró el nuevo siglo ${ }^{12}$. Poco se sabe sobre su vida, salvo que fue tan breve ${ }^{13}$ como lo fue su carrera como escritora. Únicamente escribió un libro Laissez-moi ${ }^{14}$. Laissez-moi se adentra en el pensamiento de una mujer, el de la propia escritora. Tras la ruptura sentimental, nuevamente el vacío y la soledad se entremezclan con un aspecto trascendental de su vida, la enfermedad, lo que añade un sentido trágico a su existencia y a su escritura. El propósito de esta reflexión es demostrar que tanto para Marcelle Sauvageot como para Catherine Pozzi, la escritura va unida a su respirar respondiendo a su último aliento como reflejo de ese élan escritural donde escritura y vida confluyen no pudiendo separarse, como tampoco separaríamos la piel del cuerpo, tema que acompaña la mayor parte de las reflexiones de Pozzi. Ese impulso, ese élan propio de la vida misma las llevará de forma irreme-

10. Nació el 13 de julio de 1892 en París.

11. En el salón de la escritora Mme Augustine Bulteau cuyo apodo como cronista del periódico Figaro era «Foemina», cabe destacar a la escritora Anna de Noailles. El padre de Catherine Pozzi, Samuel Pozzi, también frecuentaba otros salones, en este caso, un salón más decadente cuyo anfitrión era Robert de Montesquiou, y donde conoce a escritores como Jean Lorrain, Marcel Schwob entre otros.

12. Nació en 1900 en Charlevilles.

13. Murió el 3 de enero de 1934 en el sanatorio suizo de Davotz-Platz.

14. La primera edición de la obra de Marcelle Sauvageot se publicó en 1933, en París en la editorial La connaissance. 
diable al desarrollo de un deseo que va más allá de las palabras pronunciadas, el deseo del ser escribiente. El deseo de abrazar al ser amado durante la relación se convierte tras la ruptura en deseo de abrazar las palabras escritas. Como afirma Belinda Cannone: «Mais si écrire répond au désir, écrire est aussi une étreinte. L'étreinte -moment de la plénitude, instant où le sens ne se cherche plus, donné, offert, où le temps coule d'ineffable manière, sans urgence et sans hâte, avec grâce, sans perte» (Cannone 2000: 37).

Escribir, sería para Catherine Pozzi y Marcelle Sauvageot, un deseo de huir de la soledad de una vida que se les escapa. Escribir, sería para estas dos escritoras, una forma de retener al ser amado, evanescente, rodearlo con palabras e intentar atrapar el instante que huye del presente. Escribir es, para estas dos mujeres, recrear con palabras un modo de ser, una actitud del ser mujer, más allá de lo vivido y de lo soñado.

\section{Dos mujeres a comienzos del siglo $\mathrm{XX}$}

Ser mujer y además querer ser escritora a principios del siglo XX no era tarea fácil. Catherine Pozzi y Marcelle Sauvageot lo sabían y por eso se rebelaron. Se adelantaron a su tiempo y el tiempo de aquel entonces, no se lo perdonó. Sin embargo, el tiempo transcurrido les ha dado la razón. Tenían la suficiente capacidad intelectual, habían adquirido los conocimientos necesarios en el transcurso de sus breves vidas, de forma más o menos autodidacta si hacemos referencia a Pozzi, para poder desarrollar plenamente sus respectivas actividades creadoras. Pero la sociedad estaba cerrada y sus voces fueron acalladas. Admiradas por algunos, criticadas por otros, amadas, odiadas, pero sobre todo fueron olvidadas. Nuevamente, el tiempo les dio la razón. Despertó sus voces dormidas, y en la actualidad, van paulatinamente ocupando el merecido reconocimiento que en vida no lograron, ¿tal vez por su brevedad? O ¿tal vez por su condición de mujer?

Catherine Pozzi y Marcelle Sauvageot compartieron en vida un mismo destino, la soledad de una existencia que, irremediablemente, las conduciría a la muerte. Ambas visitaron Italia, tal y como se manifiesta en sus textos. Catherine Pozzi era de origen ${ }^{15}$ italiano por parte de padre, el célebre Doctor Samuel Pozzi. Visitó Italia en dos ocasiones, viajes que recogió en su diario. Catherine Pozzi tenía 18 años cuando por primera vez llegó a Italia con su abuela. La belleza de Venecia

15. Su ascendencia italiana se remonta al siglo XVI. Los Pozzi son originarios de Teglio, una pequeña ciudad de Valteline. (Joseph 1988: 15-17). 
no logró mitigar el estado melancólico que la caracterizó durante toda su vida. Su afán por aprender le recordó que como mujer no podía acceder a una determinada educación y que, por lo tanto, la historia del arte italiano no era más que otra de sus asignaturas pendientes. Años más tarde, en mayo de 1917, visitó Roma y se quedó deslumbrada por la Capilla Sixtina. Marcelle Sauvageot hizo alusión a su soledad cuando, tras el encuentro con el hombre amado, se hallaba sola en Venecia. Descubrió que, ante la belleza del lugar, ella seguía deambulando sola.

Ambas enfermaron de tuberculosis a temprana edad. Marcelle Sauvageot contrajo la peste blanca en 1926. Tras haber frecuentado diversos sanatorios como el de Tenay-Hauteville en la región francesa de Ain, la enfermedad se agravó con una pleuresía en 1929, provocando su muerte el 3 de enero de 1934 en el sanatorio suizo de Davotz-Platz ${ }^{16}$. Fue en el sanatorio de Tenay-Hauteville donde redactó su único libro Laissez-moi. Los primeros signos de la enfermedad pulmonar de Catherine Pozzi se manifestaron a finales del verano de 1912. Durante varios meses, la pleuresía la obligó a alejarse del mundo que la rodeaba y a refugiarse, debido a las múltiples crisis que padeció, en la escritura como medio de comunicación con el exterior y con su propio yo. Como veremos posteriormente, Pozzi contaba 10 años cuando comenzó a redactar su Journal ${ }^{17}$ y tras una larga interrupción de 7 años, lo retomó en 1913. Por vez primera desde que inició su diario y con el propósito de encontrar un sentido a su existencia debido a su enfermedad, contempló la posibilidad de dar un título a su diario. El título elegido fue De l'ovaire à l'absolu. Pozzi quiso reivindicar de este modo su condición de mujer, tanto desde su cuerpo de mujer como desde su alma. Es importante recordar llegados a este punto que, Catherine Pozzi fue una mujer que se adelantó a su época debido, por un lado, a su afán por querer alcanzar, al igual que su hermano, una carrera universitaria, y por otro lado, por su peculiar forma de concebir las relaciones entre hombres y mujeres. Como afirma Michèle Riot-Sarcey:

Le Second Empire n'a guère permis la libre expression des citoyens «égaux devant la loi». Quant aux femmes, assujetties aux règles du Code, elles ne peuvent échapper aux normes du temps [...] La comtesse Dash rédige, en 1860, Le Vrai Livre des femmes

16. La montaña mágica (1924) de Thomas Mann está ambientada en dicho sanatorio. El escritor conocía perfectamente el sanatorio de Davotz-Platz ya que su mujer Katharina Hedwig Mann había sido internada en él con frecuencia.

17. Diario íntimo que mantuvo desde 1913 hasta su muerte en 1934. Catherine Pozzi comenzó a escribir en su diario a la temprana edad de 10 años pero dejó de escribir en él durante 7 años. De ahí, que sólo se tome en consideración lo que escribió de forma ininterrumpida a partir de 1913. (Cf. Julien 2000: 15). 
(trois éditions successives), qui semble mettre un terme à tout idée d'émancipation. L'auteure incite ses congénères à se soumettre à la « loi des hommes » en respectant les lois du mariage qui, seul, ferait advenir l'existence des femmes (2002: 54).

En este sentido, y aunque Catherine Pozzi nació unos años más tarde, no se sometió a esa ley de los hombres ni de la Iglesia que pretendía reflejar un ideal de mujer: «mère, épouse, pieuse, soumise, douce et [qui] charitable, se vivifie dans le culte marial» (Riot-Sarcey 2002: 54), como veremos en la segunda parte de este estudio. En ese contexto, que no era favorable a su emancipación ni como mujer ni como escritora, la situación privilegiada de su familia ${ }^{18}$ la llevó a codearse con grandes escritores como Marcel Schowb que fue su mentor, y sobre todo a querer estudiar a pesar del rechazo de su familia que no veía con buenos ojos que quisiera ir a la universidad. Catherine se marchó a Inglaterra donde prosiguió con sus estudios demostrando su interés en materias filosóficas ${ }^{19}$ a la vez que recibía clases de música y química. Algunas de estas asignaturas no eran consideradas apropiadas para ser estudiadas por una mujer. Sin embargo, para Pozzi seguir estudiando era una manera de afianzarse como mujer pero, sin lugar a dudas, era una manera de desarrollar su proyecto de vida, un ensayo metafísico llamado De Libertate $^{20}$, que nunca llegó a concluir y con el que intenta explicar por qué el alma y el cuerpo no se pueden separar. Además pretendía demostrar que existía una predestinación propia a cada individuo fruto por un lado de los condicionamientos familiares here$\operatorname{dados}^{21}$, y por otro de las faltas cometidas durante la propia existencia. Sobre su enfermedad afirma que:

La maladie est de ma faute, entièrement, comme tous les maux humains: je regarde dans le passé sa cause exacte, dont le nom est passion, égoïsme et violence... Mais siglo XX.

18. Su padre, Samuel Pozzi, fue uno de los ginecólogos más prestigiosos del París de principios del

19. Recordemos que gracias a la Loi Camille Sée, en 1880, la escuela pública autoriza a las chicas a estudiar pero sigue presentando ciertas diferencias con respecto a la enseñanza masculina: «Cependant, de grandes disparités subsistent encore: la philosophie, le latin, le grec ne figurent pas au programme et, dans les matières scientifiques (sciences naturelles, mathématiques) quelques notions très générales sont alors jugées suffisantes» (Riot-Sarcey 2002: 61).

20. Ensayo filosófico que comenzó a redactar en 1915 y que nunca terminó. Las últimas páginas adoptan más la forma un diario que de un ensayo.

21. En este sentido, podemos poner de manifiesto el auge de la teoría psicoanalítica freudiana en cuanto a la hipótesis freudiana sobre las nociones de tradición y memoria, nociones que sin lugar a dudas Catherine Pozzi debía conocer tal y como lo demuestra en su ensayo De Libertate, conocido bajo el título de Peau d'âme. En la actualidad y dentro de los estudios psicoanalíticos freudianos, podemos hablar de memoria transgeneracional. 
à présent il n'est plus dans mes mains de la diriger ou de la finir... Nous tissons aveuglement une trame qu'il n'est pas en notre pouvoir de briser (Joseph 1988: 116).

Durante su larga enfermedad visitó varios sanatorios sin encontrar en ellos la tan ansiada curación, y como en el caso de Marcelle Sauvageot, cada nueva recaída suponía un paso más hacia la muerte.

Pero si hay un antes y un después en la escritura de Catherine Pozzi, ese proceso vino marcado por un acontecimiento trascendental que, de forma bidireccional $^{22}$, marcó la vida de las dos personas implicadas. El encuentro entre Catherine Pozzi y Paul Valéry se produjo el 17 de junio de 1920. Catherine Pozzi creyó haber encontrado por fin en Paul Valéry un hombre con el que poder compartir sus aspiraciones como escritora. El 12 de julio tras enviarle unas hojas del De libertate escribió en su diario:

C'est à présent que je suis votre prisonnière, puisque vous tenez deux feuilles du $D e$ Libertate entre vos mains. C'est à présent que j'ai joué mon destin [...] C'est à présent que j'ai joué le coup de dés dont, si je le perds, je sais je serai vieille en une minute pour toutes les minutes à venir.

[...] Quel besoin ai-je que vous preniez mes mains tendues ? Quel besoin que vous vouliez jouer à ce dialogue qui rend fou, à ce jeu de voir son visage, le même, en l'esprit qui est différent mais pareil ? Ou il a compris De Libertate, ou non. S'il ne l'a pas compris, pour qui l'écrire ? Car pas un monde, s'il ne l'entend, ne l'entendrai. S'il ne l'a pas compris, pourquoi vouloir qu'il me parle ? Il n'est pas moi (Pozzi 1987: 135).

Esta afirmación de la escritora puede resultar en cierta medida contradictoria con su actitud independiente. Pero esto no es así. Para Pozzi, Paul Valéry supuso, al menos durante los primeros años, un compañero con el que poder compartir en igualdad no sólo una relación amorosa sino sus proyectos de escritura. Ansiosa por la falta de respuesta, el 21 de julio escribió lo siguiente: «Vous ne m'avez pas répondu» (Joseph 2006: 30). Llena de dudas y temores se preguntó si ese encuentro tenía algún sentido. El 22 de julio la tan ansiada respuesta llegó. Catherine Pozzi emprendió con fuerzas renovadas su ensayo metafísico: «Vivre. Travailler, consentir à moi-même. Atteindre, en allant au bout de ma raison, le point extrême où, peut-être vous m'attendez» (Pozzi 1987: 137).

22. Muestra de ello la podemos encontrar en el Journal de Catherine Pozzi y en los Cahiers de Paul Valéry, en la correspondencia que mantuvieron durante su relación y en poemas que ambos escribieron. 
La relación entre Catherine Pozzi y Paul Valéry se prolongó a lo largo de 8 años de forma intermitente. Cuando Pozzi entabló la relación con Valéry, la escritora se encontraba en pleno proceso de divorcio del que había sido su marido, el dramaturgo francés Edouard Bourdet. Paul Valéry también estaba casado con Jeannie Gobillard, y seguiría estándolo hasta el final de sus días. Sin embargo, en este sentido Catherine Pozzi demostró una vez más ser una mujer atemporal. Llevó a la práctica hasta límites insospechados su forma de concebir el amor reivindicando en su relación con Valéry una completa unión entre el alma y el cuerpo tanto a nivel personal como a nivel literario. «I am two» le escribió a Paul Valéry en una carta en 1920. ¿Quizá Valéry no estaba preparado para afrontar una relación tan tormentosa y sincera como la que le ofrecía Pozzi? o ¿Acaso el poeta quería huir de un capítulo pasado? Recordemos que, durante un cierto tiempo y tras la primera crisis existencial padecida en 1892, fruto de la cual comenzó a redactar sus Cuadernos $^{23}$, Paul Valéry se había negado a escribir poesía. Temeroso tal vez de sus propios sentimientos, el escritor no pudo responder satisfactoriamente al desafío de entregarse por completo al amor de Pozzi.

Si la relación entre ambos fue determinante para el proyecto escritural de Catherine, a pesar del rechazo ${ }^{24}$ constante que supuso para Pozzi cualquier mención que se le hiciera de la obra y notoriedad alcanzada por Valéry tras su ruptura, es curioso observar cómo, nuevamente, el tiempo le volvió a dar la razón. Eclipsada casi totalmente de la vida de Paul Valéry por voluntad propia, y silenciada ${ }^{25}$ por deseo expreso en su testamento, la posteridad con la publicación de los Cuadernos de Valéry y con el Journal de Pozzi ha demostrado que Catherine Pozzi tuvo un rol esencial en la obra de Paul Valéry, así como también lo tuvo Valéry en la de Pozzi. Sus últimos poemas ${ }^{26}$, Vale, Ave, Scopolamine, Nova, Maya, Nyx, son la

23. Escritos de 1894 a 1945 y publicados póstumamente.

24. Catherine Pozzi lo acusó de haberle robado algunas ideas y de no haberla alentado a terminar su ensayo filosófico. Al inicio de su relación con Paul Valéry, Catherine Pozzi le mandó su manuscrito que éste le devolvió sin ningún tipo de comentario. «Elle invoque ensuite le chagrin qu'elle avait éprouvé en retrouvant ses idées reformulées dans divers ouvrages de Valéry, à partir d'Eurêka. Si elle n'a pas encore achevé son livre, la faute, à son avis, en revient en grande partie à Valéry qui n'avait pas voulu qu'elle le finisse » (Joseph 1988: 287).

25. En 1929 tras su ruptura, Catherine Pozzi deja por escrito en su testamento la orden de quemar toda la correspondencia que mantuvieron con la finalidad de borrar cualquier vínculo con el escritor.

26. Publicados en 1935 en La Nouvelle Revue Française. El 5 de noviembre de 1934, Catherine Pozzi escribió en su diario el poema $N y x$ dedicado a Louise Labé. Y un día más tarde, en la noche del 6 al 7 de noviembre, confirma en su diario haberlos escrito: «J'ai écrit VALE, AVE, MAYA, NOVA, SCOPOLAMINE, NYX. Je voudrais qu'on en fasse une plaquette» (Pozzi 1987: 658). Del 28 al 29 de septiembre de 1931 por la noche, Catherine Pozzi escribió en su diario el poema SCOPOLAMINE (Pozzi 1987: 587). 
prueba de que pasado y presente se funden para conformar un futuro más allá de lo vivido. Sin embargo, y como suele suceder en la mayoría de los casos cuando se trata de una escritura de mujer, las distintas historias literarias al igual que la sociedad «a cherché à interdire la création aux femmes. A l'étouffer dans l'oeuf. Comment?» (Wilwerth 1987: 11). Relegándolas a su naturaleza de mujer, es decir la mujer es cuerpo pero un cuerpo cuya única función es la procreación. Apartadas así de toda capacidad de creación artística, las mujeres vivieron recluidas en su papel femenino de madres y esposas. En este sentido, la producción literaria de Catherine Pozzi fue durante mucho tiempo desconocida, excepto por un sector muy específico, y si era mencionada lo era a través de los estudios sobre Paul Valéry. Ya hemos visto hasta qué punto esta situación hubiera desagradado a la propia escritora, sobre todo si tenemos en cuenta que para Paul Valéry, Catherine Pozzi era la amada que no debía ser nombrada. Los actuales estudios sobre la literatura escrita por mujeres nos demuestran que Catherine Pozzi, al igual que otras escritoras, también sabían crear, escribir, y que los tópicos heredados e implantados en la sociedad logocéntrica no eran más que eso, tópicos sin fundamento.

En el caso de Marcelle Sauvageot, lo efímero de su existencia parece ser la clave tanto de su obra como de su vida. Su única obra Laissez-moi es un largo grito de dolor ante la pérdida del amor, pero sobre todo ante la pérdida de la ilusión como única forma de seguir luchando contra la enfermedad. Escrita durante un fuerte rebrote de la enfermedad, tras la ruptura amorosa, la obra sigue, a pesar de la angustia que reflejan sus palabras, siendo capaz de trasmitirnos un grito de esperanza, de abrir una puerta a la ilusión, de intentar erradicar la soledad más allá de un destino. En definitiva, Laissez-moi nos muestra a una escritora que, al igual que Catherine Pozzi, hizo prevalecer su forma de pensar y su condición de ser como mujer por encima de las normas preestablecidas. Podemos afirmar una vez más que el tiempo les dio la razón.

\section{Dos escritoras a comienzos del siglo $\mathrm{XX}$}

Además de la enfermedad que las mantuvo apartadas durante largas temporadas internadas en distintos sanatorios, de la brevedad de su existencia y de la soledad que las llevó a la escritura, compartieron una misma inquietud: construir un mundo más allá de lo vivido. Y ese mundo construido, recreado, sólo podía existir por medio de sus textos. Pozzi tiene una amplia producción literaria que abarca diversos géneros: diario, ensayo filosófico, correspondencia, novela autobiográfica, poesía. Sauvageot únicamente escribió un libro, una breve narración autobiográfica en forma de cartas destinadas a un hombre cuyo nombre nunca será revelado. Una 
vez más, entre ambas un mismo denominador común sobrevuela sus escritos, escribirse en el devenir del texto.

Catherine Pozzi y Marcelle Sauvageot se adentraron en ese terreno siempre movedizo «des écritures du moi» ${ }^{27}$. Como dice Gusdorf: «Le commencement des écritures du moi correspond toujours à une crise de la personnalité ; l'identité personnelle est mise en question, elle fait question ; le sujet découvre qu'il vivait dans le malentendu» (1990: 23). Pozzi tuvo una de sus primeras crisis existenciales cuando empezó a dudar del amor que su padre, al que adoraba, le profesaba. Entre ambos se había desarrollado una intensa correspondencia que llevó a su madre a exclamar escandalizada: «Mais ce sont des lettres d'amant!» (Joseph 1988: 25). Recordemos que su padre el doctor, Samuel Pozzi, fue todo un seductor del París de principios de siglo $\mathrm{XX}$, que mantuvo relaciones con numerosas mujeres entre las que cabe destacar su amistad con la actriz Sarah Bernhardt. Esa primera crisis la acompañó a lo largo de toda su vida, tal y como se refleja en su diario, cartas y otros escritos, a través de la constante búsqueda de un ser amado que fuera el reflejo de un padre ausente. La crisis existencial que llevó a Marcelle Sauvageot a escribir difiere en cierta medida de la de Catherine Pozzi, debido en parte a la diferencia de edad que tenían cuando empezaron a escribir. Sauvageot ya era una mujer cuando escribió la carta que daría lugar a Laissez-moi, Pozzi todavía era una niña de 10 años cuando comenzó a escribir su diario. Pero ambas lo hicieron porque ante ellas se hallaba el vacío por la pérdida del amor pero sobre todo por la pérdida de una ilusión necesaria para seguir viviendo-existiendo. Ambas utilizaron las cartas como un medio de expresión de sí mismas y una forma de llegar al ser amado.

La literatura epistolar fue en su principio un género masculino como lo atestiguan las cartas de Platón, Aristóteles... Sin embargo, y en el transcurso de los siglos, pasó a ser un género propio de la literatura escrita por mujeres ${ }^{28}$. Si las cartas se han considerado un género menor dentro de la literatura ¿cómo no iban a ser un espacio en el que la mujer pudiera desarrollar su capacidad creativa sin invadir el terreno masculino de la literatura noble? El género epistolar femenino permitía la comuni-

27. Referencia al magnífico estudio Les écritures du moi (1990) de Georges Gusdorf.

28. Se han llevado a cabo numerosos estudios sobre la literatura epistolar como género femenino, señalaremos únicamente alguno de ellos como el estudio dirigido por Christine Planté, L'épistolaire, un genre féminin? publicado en 1998, o Lettres de femmes: textes inédits et oubliés du XVIe au XVIIIe siècle de Elisabeth C. Goldsmicht y Colette H. Winn, publicado en 2005. También destacar las actas del Coloquio de Cerisy-La-Salle, celebrado del 1-5 de octubre de 2003 y publicado en 2006, bajo la dirección de Brigitte Diaz y Jürgen Siess, con el siguiente título: L'épistolaire au féminin. Correspondances de femmes XVIIIeXXe siècle. 
cación entre el mundo privado y el mundo exterior. Marie-Claire Grassi apunta a este respecto que el género epistolar es, además de la expresión de una literatura marginal, una manifestación de una sensibilidad considerada extraña a lo masculino. Por lo tanto, sería sencillo relacionar la literatura epistolar con la escritura femenina y la marginalidad (1998: 3). Para Evelyne Wilwerth: «Les écrivaines (surtout au $\mathrm{XVII}^{\mathrm{e}}$ et au $\mathrm{XVIII}{ }^{\mathrm{e}}$ ) s'emparèrent de cette plume de chambre et s'adonnèrent passionnément à cette forme d'écriture» (1987: 19). Las mujeres siempre tuvieron menos posibilidades de ser publicadas que los hombres. Los editores se mostraban reticentes a la hora de publicar textos de mujeres. Esto llevó a muchas escritoras a adoptar pseudónimos masculinos ${ }^{29}$ que les permitieran esconder su verdadera condición femenina. La sociedad no veía con buenos ojos que la mujer quisiera escribir más allá de lo privado, y publicar suponía alcanzar una cierta notoriedad y visibilidad. Tal y como afirma Béatrice Didier en L'écriture-femme:

Une fois accepté, plus ou moins consciemment, que la publication était exclue, pourquoi alors ne pas épancher son désir d'écrire dans la lettre -d'autant plus proche du roman que ce genre prend volontiers la forme de lettres fictives ? (1991: 15).

Así, la literatura escrita por mujeres nos ha dejado a lo largo de su historia grandes intercambios epistolares reales como la intensa correspondencia entre Héloïse y Abélard, las cartas de Mme de Sévigné a su hija, las correspondencias de Ninon de Lenclos, de Marie du Deffand, de Julie de Lespinasse, de Françoise-Eléonore de Sabran, de George Sand, de Colette, d'Anna de Noailles, de Catherine Pozzi, de Mireille Sorgue... la lista sería sin duda interminable. La literatura femenina epistolar también nos ha legado un buen número de correspondencias ficcionales como les Épistres familières et invectives (1539) de Hélisenne de Crenne, Lettres d'une péruvienne de Madame de Graffigny (1747), Lettres de mistriss Fanni Butlerd (1757) de Madame Riccoboni, Vingt-quatre heures d'une femme sensible (1824) de Constance de Salm, entre otras. Laissez-moi de Marcelle Sauvageot se enmarca dentro de este tipo de correspondencia. Gusdorf señala que: «la correspondance s'inscrit dans une relation de réciprocité» (1990: 152). Pero en el caso de las cartas escritas por Marcelle Sauvageot, éstas nunca llegaron a su destinatario puesto que no fueron enviadas por deseo propio de la escritora. En este sentido, la relación epistolar es únicamente unidireccional, yendo de un yo presente (el de la autora) a un yo ausente (el del destinatario, real, pero ajeno a la existencia

29. Recordemos en el siglo XIX el célebre caso de la escritora George Sand, cuyo verdadero nombre era Aurore Dupin. 
de dichas misivas). Veremos a continuación la repercusión de Laissez-moi desde que se gestó en la mente de Marcelle Sauvageot hasta la actualidad.

En 1930 Marcelle Sauvageot ingresó en el sanatorio de Tenay-Hauteville tras su última recaída. Durante el viaje en tren que la condujo hasta el centro de salud, comenzó a redactar una larga misiva ${ }^{30}$ que nunca envió y cuyo destinatario nunca quiso revelar. Escritas entre el 7 de noviembre de 1930 y el 24 de diciembre de ese mismo año -la última carta no está fechada- las conservó para sí durante tres años negándose a su publicación. La primera edición ${ }^{31}$ de la obra se realizó en 1933. Se editaron 163 ejemplares que no salieron a la venta, pero sí se repartieron entre los numerosos amigos de Marcelle Sauvageot. Un año después se publicó la segunda edición bajo el título de Commentaire ${ }^{32}$, con un prólogo de Charles du Bos, amigo de escritores de reconocido prestigio como Paul Claudel, André Gide, Paul Valéry o Marcel Proust, entre otros. La escritora murió poco antes de su publicación.

Reeditadas ${ }^{33}$ posteriormente en 1936 y en 1943, no se volvieron a editar ${ }^{34}$ hasta 1986. Y de nuevo, cayeron en el olvido. Sin embargo, gozaron de una gran repercusión tras la segunda edición. Aclamadas por diversos escritores, lo fueron de forma particular por Clara Malraux quien destacó su carácter no convencional al afirmar: «Premier livre écrit par une femme qui ne soit pas de soumission... Livre de tristesse noble, livre de dignité! Admirable» (1973: 283), o «Commentaires aurait dû être une date dans la littérature féminine» (1973: 283). Según Paul Valéry, dicha obra: «Témoigne d'une vie mentale exceptionnelle, singulièrement divisée contre soi-même».

Olvidada desde su última publicación en 1986, Commentaire se volvió a editar diez años más tarde. Publicada en la misma editorial, esta nueva edición presenta una variante con respecto a la edición de 1986. Junto al título Commentaire, se le ha añadido el subtítulo de Récit d'un amour meurtri ${ }^{35}$ lo que permite al lector acceder más fácilmente al contenido de la obra. En 2003, esta nueva edición adquiere por fin su propia seña de identidad. El cambio de título propuesto por el nuevo editor ${ }^{36}$ será determinante en el resurgir de la obra. Laissez-moi: Commentaire provoca la vuelta

30. Nos referimos a la primera de las cartas que escribió y que nunca envió.

31. Publicada en la editorial La connaissance.

32. Fue el propio editor el que dio el título a las cartas.

33. Nueva edición, revisada y aumentada por fragmentos póstumos recogidos par Jean Mouton.

34. Editorial Critérion.

35. Esta edición se ha visto ampliada con cartas de escritores a Jean Mouton.

36. Publicada en la editorial Phébus. 
a escena de Marcelle Sauvageot, y en esta ocasión supuestamente de forma definitiva. Desde su primera aparición en el panorama editorial hasta la actualidad, se conocen varias ediciones ${ }^{37}$. Adaptada al teatro en 2005 de la mano de Laetitia Masson, el papel de la escritora fue interpretado por la actriz francesa Elsa Zylberstein. Traducida también al castellano con el título, Déjame y al catalán, Deixa'm por Rba editores en 2004, también se tradujo al italiano, Lasciami sola, en 2005. Anteriormente, en 1939 había sido traducida al alemán bajo el título de Kommentar.

La recepción de las obras de Catherine Pozzi fue determinante para que la autora alcanzara el tan ansiado reconocimiento, aunque en el caso de Pozzi dicho reconocimiento es contradictorio ya que depende en gran medida de la negativa de Catherine Pozzi a firmar con su propio nombre. Ya hemos mencionado que la actividad literaria de Pozzi fue intensa tanto como lo fueron su vida y sus relaciones. Empezó a redactar un diario a la temprana edad de 10 años publicado varios años después de su desaparición. La primera edición ${ }^{38}$ que se tiene de él data de 1990. El 2 de marzo de 1992, dos años después de su publicación, Philippe Lejeune exclamaba lo siguiente: «Nouveau coup de foudre: Catherine Pozzi. Ça ne surprendra pas ceux qui ont lu son journal d'adulte, le plus beau qu'on ait publié ces dix dernières années» (1993: 79). Y tras leer su diario de adolescente, su admiración es aún mayor si cabe: «Pour la première fois j'ai l'impression de lire le journal d'une jeune fille moderne» (1993: 80). En este sentido, la admiración de Lejeune por la modernidad de Pozzi nos permite resaltar una vez más la frase leitmotiv: «El tiempo transcurrido les ha dado la razón [...] fueron dos mujeres que se adelantaron a su época» con la que iniciamos nuestro recorrido por la vida y obras de estas escritoras. En efecto, Pozzi demostró desde sus comienzos que ser mujer no significaba acatar las reglas sociales impuestas sino que, ser mujer, era ante todo luchar por una actitud de no sumisión, de resignación ${ }^{39}$ ante su condición femenina, como así lo hizo también Marcelle Sauvageot.

En 1922 empieza a escribir un relato Agnès, autorretrato de sí misma adolescente, publicado por primera vez el 1 de febrero de 1927 en la Nouvelle Revue

37. Destacamos la edición Des femmes en 2004, editorial francesa y de referencia dedicada exclusivamente a la edición de textos escritos por mujeres. En este caso, Laissez-moi presenta una grabación sonora a cargo de la actriz francesa Fanny Ardant.

38. Edición a cargo de Lawrence Joseph.

39. Philippe Lejeune tras la lectura de su diario de adolescente pone de manifiesto la situación de enclaustramiento que padecían las jóvenes que permanecían en internados: «Ce n'était pas le journal qui était la prison, mais l'adolescence des jeunes filles. Littéralement sous haute surveillance. Leur chambre est un quartier de haute sécurité [...] On leur enseigne la résignation» (1993: 83). 
Française y firmado por un misterioso o misteriosa desconocida C.K $\mathrm{K}^{40}$. Esto suscitó múltiples conjeturas ${ }^{41}$ sobre la identidad del autor, llegándose incluso a barajar como posible autor al propio Paul Valéry, hecho que enfureció a Catherine. Como apunta Lawrence Joseph (2006: 19), el director de la Nouvelle Revue Française, Jean Paulhan consiguió averiguar que tras esas iniciales se escondía Catherine Pozzi, y le propuso publicar uno de sus poemas $A v e^{42}$, el único editado en vida de la escritora. Agnès ha presentado varias ediciones desde 1927 y se tradujo al alemán ${ }^{43}$ un año después. Pozzi proyectó una segunda parte de este relato, Agnès II, una ficción autobiográfica en la que Pozzi se convierte en Strozzi: «où les noms de certains personnages sont à peine transposés: ainsi, Pozzi devient Strozzi» (Joseph 1988: 255), que finalmente abandonó.

Ya hemos mencionado la importancia de la correspondencia en la vida de $\mathrm{Ca}$ therine Pozzi. Sin lugar a dudas, la más intensa fue la que mantuvo con el escritor Paul Valéry hasta el final de su relación. Tras su ruptura y a pesar de seguir reci-

40. C.K. Iniciales de Catherine a la que llamaban cariñosamente Karin.

41. Tal y como señala Lawrence Joseph en su estudio Une robe couleur de temps: «Le succès d'Agnès est instantané et provoque beaucoup de conjectures sur l'identité de l'auteur. C'est en premier, à Valéry lui-même qu'on attribue Agnès, mais le bruit court aussi que l'auteur du conte pourrait être sa fille, Agathe, ou le peintre Marie Laurencin» (Joseph 1988: 248).

42. Publicado en La Nouvelle Revue Française en 1929. Catherine Pozzi escribió en su diario en la noche del 31 de diciembre de 1928, la primera versión de Ave que reproducimos a continuación:

Très haut amour, s'il se peut que je meure

Sans avoir su d'où je vous possédais,

En quel Soleil était votre demeure,

En quel passé votre temps, en quelle heure

Je vous aimais.

Très haut amour dont je n'ai pas mémoire

Si je m'endors sans avoir retrouvé

En quel sommeil se voyait votre gloire

Quel vous étiez, dont je tiens mon histoire,

Mon bien-aimé,

Retrouvez-moi pour moi-même perdue,

Feu sans foyer dont j'ai fait tout mon jour !

Soyez demain la ténèbre inconnue,

Soyez la mort, amour (Pozzi, 1987: 476-477).

43. En su diario, Catherine Pozzi hacía referencia a esa traducción: «Le soir du jour où j’ai reçu les 5 premiers exemplaires de l'Agnès allemande, j'ai pu penser, après être au lit, que ma vie n'était plus la même depuis que j'existe pour des milliers d'inconnus. L'Agnès française n'avait pas d'auteur, l'Agnès allemande s'appelle Catharina Pozzi (les trois «a» sont deux)» (Pozzi 1987: 431). 
biendo cartas de Valéry, Catherine Pozzi se negó a responderle, no abriéndolas, e incluso en una ocasión le pidió a su hijo, Claude Bourdet, que le contestara rogándole que no volviera a escribirle más.

En 1935 el ensayo metafísico que había comenzado a escribir vio la luz póstumamente. Catherine Pozzi escribió en su diario el 20 de noviembre de 1933 lo difícil que le resultaba, dado la gravedad de su estado de salud, el seguir trabajando en dicho ensayo: «Incapacité de continuer à refaire la 2 partie de $P . d^{\prime}$ ' $A$, parce que je n'ai plus d'impulsion vers rien à cause de la solitude absolue» (1987: 633). Si el diario ${ }^{44}$ supone para Pozzi un desdoblamiento de su propio yo, un diálogo constante consigo misma, un reflejo de su yo pensante, un libro abierto en constante evolución, también refleja de forma minuciosa su propia concepción de la escritura. Pero en el caso de Pozzi, el diario viene marcado además por un factor trascendental en su vida: el tiempo y la soledad. Pozzi era consciente de que su vida se iba acortando en cada nueva recaída. Gusdorf señala que: «le rédacteur du journal ne connaît pas la fin de l'histoire» (1990: 319), Pozzi sabía que el tiempo se le escapaba. En algunos casos, la escritora escribía primero en su diario ciertas frases, ideas que luego recogía en sus textos. Pozzi intentó definir su forma de escribir y lo hizo como si se tratase de un problema matemático que el lector debía resolver:

Mon style consiste en mots qui s'appellent ; celui-ci nous amène donc immédiatement au cœur de la question. Il y a deux systèmes:

a) Tout raconter comme s'il fallait mettre un lecteur au courant de « de ce qui s'est passé avant » pour l'intéresser aux personnages.

b) Ne dire algébriquement que ce dont j'ai besoin pour mon état des lieux.

Second parti adopté ; pas de lecteurs ni en vue ni que mon caractère descende à désirer. Ceci est une œuvre utilitaire, mono-utilitaire. On n'y mettra pas en épigraphe l'admirable mot de Gourmont: « Chez la femme, l'intelligence a toujours une odeur de sexe » (1987: 22).

De Libertate, título originario del proyecto, pasó a ser en 1930 Le corps de l'âme y finalmente Peau d'âme, reeditado en numerosas ocasiones desde 1935 hasta 1990. Con la finalidad de aunar ambas partes del ser humano (corps y âme), Catherine Pozzi propone por medio de un juego intertextual un nuevo título a su ensayo filosófico Peau d' âme, haciendo alusión mediante un juego de palabras fonético «âme» y «âne» al célebre cuento popular Peau d'âne (1694) de Charles Perrault.

44. Véase a este respecto Les écritures du moi (Gusdorf 1990: 317). 
Recordemos que en el cuento de Perrault, la princesa escapa del castillo paterno cubriéndose con la piel de un asno, lo que le permite esconder su verdadera identidad. Para Pozzi, debajo de la piel se esconde el alma, pero la piel y el alma no se pueden separar ya que conforman un todo. Si el cuerpo sufre también lo hará el alma y si el alma del ser humano se siente infeliz, esa infelicidad dejará huellas en su cuerpo. De ahí que Catherine Pozzi se sienta en parte culpable de su enfermedad debido a su propia infelicidad: «La maladie est de ma faute» (Joseph 1988: 116).

Si ya hemos mencionado su inconformismo por la situación de opresión padecida por las mujeres, Catherine Pozzi al igual que Renée Vivien logró exaltar en sus poemas, tal y como apunta Camille Aubaud: «des états d'âmes spécifiques à leur sexe et à affirmer une langue féminine qui, par son raffinement, son lyrisme, sa musicalité, apporterait une nouvelle gloire à la poésie et au roman: la gloire d'être femme» (1993: 144). Tras su desaparición, sus poemas se publicaron en 1935 con las iniciales C.K., y se siguen reeditando.

\section{Escribir la voz del otro en la soledad de la reclusión}

Laissez-moi de Marcelle Sauvageot y Agnès de Catherine Pozzi son dos breves relatos autobiográficos cuyo tema central es el amor, la pérdida de la esperanza en el caso del relato de Marcelle Sauvageot, o la búsqueda desesperada del amor en Agnès de Catherine Pozzi. Ambas reflejaron en su escritura la soledad del ser ante la enfermedad. Recluidas en sanatorios y apartadas del mundo que las rodeaba, intentaron escribir la voz del otro, una voz evanescente pero necesaria para sobrevivir tanto física como psíquicamente.

\subsection{Del yo presente al yo ausente en Laissez-moi de Marcelle Sauvageot}

Una carta de despedida anuncia la ruptura de la relación amorosa existente entre la escritora, Marcelle Sauvageot, y el ser amado llamado afectuosamente «Bébé». La crítica ha visto en ese dato que, tras ese apelativo cariñoso, se escondía un hombre más joven que ella: «Le jeune homme vêtu de noir aux yeux qui se donnaient me plut; je l'appelai "Bébé" et je lui parlai tous les jours» (Sauvageot 2005: 51). Nadie hasta la fecha ha podido afirmar a ciencia cierta de quién se trataba. También sabemos que él la llamaba cariñosamente: «Vous m’appeliez "ma grande”; j’étais celle qui devait tout connaître et vous celui qui devait tout entendre» (Sauvageot 2005: 24). Pero no se ha aportado ningún dato más sobre la identidad del destinatario de las cartas que la escritora redactó y nunca envió. El 7 de noviembre de 1930, en el tren que la llevaba de nuevo al sanatorio, comenzó a escribir la primera carta, una especie 
de comentario (de ahí el título que acompañó las primeras ediciones de la obra) o reflexión sobre la carta recibida en la que el joven le anunciaba su inminente boda. Como lectores, accedemos a las palabras del ser amado, de «Bébé» por medio de la voz femenina de la escritora que inicia su andadura metatextual tomando como punto de partida la voz del otro en su relato. Siguiendo el orden reflexivo y escritural de las cartas de Marcelle Sauvageot, hemos extraído los fragmentos de la carta recibida con el fin de determinar de qué manera el proceso de asimilación de las palabras enviadas por el remitente-Bébé- condiciona subjetivamente al destinatario -la propia escritora- en el proceso de escritura de las cartas de Marcelle Sauvageot. Las últimas palabras escuchadas antes de su partida hacia el sanatorio así como la carta que el joven le envió son el detonante del impulso escritural de Sauvageot. En definitiva, se trata de determinar cómo el fenómeno metatextual interfiere en el proceso escritural del libro que se escribe.

A continuación hemos señalado tal y como se presenta en Laissez-moi las últimas palabras escuchadas por Marcelle Sauvagot antes de dirigirse al sanatorio, así como determinados fragmentos de la carta de ruptura ${ }^{45}$ enviada por Bébé y recibida por la escritora. La escritora los va desmenuzando a la vez que su relato avanza:

1. Tu vois là une preuve d'amour, n'est-ce pas? (Sauvageot 2005: 7).

2. Je me marie... Notre amitié demeure... (Sauvageot 2005: 19).

3. Je sais que maintenant vous êtes malade sérieusement. Mais ce n'est certainement pas par dévouement pour un autre que vous avez eu cette maladie (Sauvageot 2005: 23).

4. Vous que j'ai tant aimée... (Sauvageot 2005: 25).

5. Obligé ... peur de décevoir (Sauvageot 2005: 33).

6. J'en avais assez (Sauvageot 2005: 43).

7. Sans doute aviez-vous raison, je le sais... mais qui sait ce qui serait arrivé si vous n'aviez pas eu raison? (Sauvageot 2005: 47).

8. Je sais que ce que je vous écris pourra vous sembler contradictoire... ne pas tenir debout (Sauvageot 2005: 48).

9. Si l'occasion s'en présentait... (Sauvageot 2005: 62).

10. Cette petite place dans mon cœur (Sauvageot 2005: 62).

11. Votre affection (Sauvageot 2005: 70).

45. El lector estaría casi tentado por intentar recomponer la carta tal y como habría sido recibida por Marcelle Sauvageot. Le gustaría incluso poder reconstruir ese puzle propiciado por las reflexiones suscitadas por la autora, y tejidas en el hilo escritural de unas voces entrelazadas pero en este sentido sólo nos queda la carta fragmentaria que la autora va desgranando. 
La voz del otro, la voz del joven se entremezcla con la de la escritora por medio de la citación textual. El entrecomillado en las cartas que la escritora redacta nos indica que esa voz es la del otro, la del ser amado, un yo presente en su mente pero ya ausente de su vida. Como si la voz estuviera en lo más profunda de su ser, la escritora reflexiona sobre su relación con él, intentando desentrañar la causa de la ruptura. Progresivamente, las cartas de Marcelle Sauvageot constituyen una reflexión a partir de las palabras de él, una forma de respuesta introspectiva puesto que el diálogo que caracteriza toda la correspondencia nunca se llevó a cabo.

«Tu vois là une preuve d'amour, n'est-ce pas» (Sauvageot 2005: 7), frase leitmotiv que se repite a lo largo de toda la primera carta de Sauvageot y con la que se inicia Laissez-moi. Como si tratara de dejarse acunar por el dulce traqueteo del tren que la conducía de forma irremediable a su nueva morada, la escritora retomó una y otra vez la frase pronunciada por los labios del ser amado, la última que él le había dicho antes de su partida, la frase que no podía olvidar porque veía en ella el presagio de un final cada vez más próximo. Recordó la conversación mantenida la última noche. Recordó el dolor, la ansiedad al no conseguir transmitir sus propias emociones: «Comment pouvoir faire sentir tout le bouleversement que produit une émotion au moment précis où elle a lieu?» (Sauvageot 2005: 8) se preguntó la escritora. Pero la frase, nuevamente, le recordó que él no la amaba: «Que faut-il croire de cette phrase? Je sais que tu ne m'aimes plus. Avec quel soin comique évites-tu de me dire: «Je vous aime!»» (Sauvageot 2005: 9).

Finalmente llegó la carta, la tan temida misiva que rompería sus deseos de curación, sus sueños amorosos, recordándole que todo no había sido más que una ilusión: «Je me marie... Notre amitié demeure...» (Sauvageot 2005: 19), con esas palabras Bebé dio por finalizada su relación con ella. Al igual que para Catherine Pozzi, para Marcelle Sauvagot el dolor producido por la ruptura no es únicamente un dolor que tiene lugar en el alma, es un dolor que se siente en la piel:

Je suis restée tout à fait immobile et la chambre a tourné autour de moi. Dans mon côté, là où j'ai mal, peut-être un peu plus bas, j'ai cru qu'on coupait la chair avec un couteau très tranchant (Sauvageot 2005: 19).

Sin embargo, el tiempo no logró mitigar la herida, y el dolor fue aumentando. $\mathrm{Al}$ dolor físico provocado por la enfermedad se le unió el dolor emocional por la pérdida no sólo del ser amado sino por la pérdida de una ilusión construida y alimentada en lo más profundo de su ser. Alma y cuerpo se fusionaron una vez más ante la desesperanza: 
Il y aura le réveil au petit matin, quand la souffrance est là encore impuissante et qu'on prie le Seigneur de vous laisser dormir encore. C'est comme une tumeur enveloppée d'ouate: et tout à coup un élancement violent se fait sentir [...] Dans la journée ou le soir, il y a des moments de calme, pendant lesquels on est étonné de ne rien sentir ; et l'on guette la phrase, le son, le parfum qui va brusquement faire renaître le mal (Sauvageot 2005: 20-21).

Intentando saber en qué momento de su caminar él se apartó de ella, llegó a la conclusión de que no había sido de un día para otro. ¿Acaso no eran ciertas aquellas cartas donde él le manifestaba sus celos? ¿No eran ciertas aquellas sus palabras de amor? «Je ne dis pas que vous m'avez joué une comédie: seulement, ce n'est pas en un jour que vous ne m'avez plus aimée» (Sauvageot 2005: 23). A pesar del dolor causado por la ruptura, la escritora se mantuvo fiel a sus principios. Prefirió la separación a ser amada por obligación: «Obligé», «Peur de décevoir» (Sauvageot 2005: 33). Para Marcelle Sauvageot esto supuso una traición y un acto de cobardía, y no estaba dispuesta a mantener una simple amistad cuando lo que sentía por él era amor. En este sentido, podemos afirmar una vez más que la autora no esconde sus sentimientos y lanza una fuerte crítica a aquellas mujeres que aceptan casarse aun a sabiendas de no ser amadas.

J'ai seulement souri de quelques mots: « obligé », «peur de décevoir ». J'ai pensé aussi que si j'étais votre fiancée et si je lisais cette phrase, je serais attristée. Je n'aimerais pas qu'on m'épouse pour ne pas me décevoir ; pour ne pas me montrer qui on est [...] D'ailleurs votre fiancée n'a pas lu cette phrase: elle ne sait pas « ce que vous êtes ». Et si elle savait, il est probable qu'elle serait heureuse de cet hommage rendu à son amour. Une femme aimante n'est pas-elle pas ravie du choix que l'homme fait d'elle en récompense de son amour complet? (Sauvageot 2005: 33-34).

El destino de Marcelle Sauvageot y Catherine Pozzi se entrecruza de nuevo en este punto. Pozzi también le reprochó a Paul Valéry su pasividad, y sobre todo su temor a sacar a la luz su pasión.

Arrivée à peine je tombe horriblement mal [...] Paul Valéry, lui, est chez Hanotaux à Roquebrune, à 30 ou 40 kilomètres. Il m'écrit et signe t-à-t...T.A.T. signifie « tout à toi » chez les messieurs épouvantés. Je sais bien qu'il n'a pas envie de venir car sa famille pourrait l'apprendre. Mais je souffre tant qu'il me semble, je vais mourir. Je l'appelle ! Cruelle perplexité: ne pas venir est ignoble, venir est dangereux. Paul Valéry est trop intelligent pour n'avoir pas résolu ce problème (Joseph 2006: 608).

Valéry quiso a toda costa mantener su relación con Catherine Pozzi en el anonimato, de ahí, las constantes disputas entre ambos. Al finalizar su relación, ella 
escribió en su diario lo siguiente: «Le Sans-Nom, le Prudent qui ne veut pas être nommé [...]» (Joseph 2006: 610) o incluso: «ma Tête de Paris» (Pozzi 1987: 234). A lo largo de su relación y en un sus Cuadernos, Paul Valéry hizo mención a Catherine Pozzi pero siempre de forma velada ${ }^{46}$. La escritora escribió en su diario el dolor que sintió al no ser para él durante el transcurso de su vida y en sus textos más que un nombre silenciado:

Tous les soirs, revenir vous coucher à ses côtés ? Toute la nuit, m'écrire du même lit où elle dort presque emmêlée à vos membres et dormir, coïncidant à son sommeil ? Tout le jour, laisser sur sa table les cahiers où vous parlez de moi, en langage si clair à comprendre ? [...] Défendre votre sommeil où je suis et votre réveil qui dit mon nom. Et si vous le dites en dormant, mon nom, que ce soit dans le silence et qu'il ne passe pas près de la respiration de cette humanité alliée (Pozzi 1987: 179).

Para ambas mujeres, la escritura supuso una válvula de escape que les permitió trascender el estadio de forclusión del Nombre del Padre ${ }^{47}$ en el que se hallaban inmersas. Recordemos que, tanto en la vida real como en la escritura, se ven confrontadas a la imposibilidad de nombrar al ser amado. Marcelle Sauvageot para salvaguardar su identidad lo denomina Bébé, y hemos hecho mención previamente a lo difícil que le resulta a Pozzi dar un nombre real a Valéry. En Agnès, podemos destacar que la forclusión viene determinada por la ausencia de la figura paterna en la vida de Pozzi. Llama a su padre Le Docteur. La ausencia de referente paterno

46. «Elle est "Karin”, “C.K.", "ma Psyché”, "Laure”, "Le Cygne”, "Eurydiké”, "X”, "Béatrice”, "Bice", "Bce”, “B.”»... (Pozzi, 1987: 179). Como afirma Lawrence Joseph en su estudio del diario de Catherine Pozzi: «Beatrice (ou Bice, Bce, B.) est l'un des surnoms - évocateur de Dante que P. Valéry donnait à C.P. dans ses Cahiers» (Pozzi 1987: 214).

47. En su estudio sobre un caso de neurosis infantil, L'homme aux loups (1918), Freud introdujo el término «verwerfung» que, posteriormente, retomó Lacan, en 1953, en Le Séminaire sur l'homme aux loups, traduciéndolo por « forclusión », término perteneciente al campo de la teoría del Derecho. El «verwerfung» forma parte del primero de los cuatro actos psíquicos de repudio o negación señalados por Freud en el estudio de la neurosis. Para Lacan, tal y como menciona en «Le séminaire sur la lettre volée»: «c'est la loi propre à cette chaîne [signifiante] qui régit les effets psychanalytiques déterminants pour le sujet: tels que la forclusion (Verwerfung), le refoulement (Verdrängung), la dénégation (Verneinung) ellemême, - précisant de l'accent qui y convient que ces effets suivent si fidèlement le déplacement (Entstellung) du signifiant» (Lacan, 1966a: 19-20). Y es, para Jacques Lacan, una forclusión del Nombre del Padre, es decir, dicha forclusión impide al sujeto acceder al orden simbólico, a la metáfora paterna, provocando la castración simbólica del significante. La forclusión recae forzosamente en el significante del Nombre del Padre, tal y como Lacan lo había demostrado en su seminario: «Tenons pour démontrer ce que fut le cœur de mon séminaire sur les psychoses, à savoir que ce terme se rapporte à l'implication la plus nécessaire de sa pensée [Freud] quand elle se mesure au phénomène de la psychose: c'est le terme de Verwerfung» (Lacan 1966b: 73). 
en su vida llevó a Catherine Pozzi a cuestionarse a temprana edad incluso la existencia de Dios como padre de la humanidad. Durante una profunda crisis existencial, convirtiéndose en una Hérétique, la escritora reflexionó sobre la gravedad del pecado original intentando entender el motivo por el que Adán y Eva fueron expulsados del Paraíso ${ }^{48}$. Llegó a la conclusión de que, al igual que ellos, su único pecado había sido querer ampliar su propio conocimiento lo que la impulsó a vivir constantemente en estado pecaminoso. De ahí que a lo largo de toda su vida hubiera intentado dar una explicación a la existencia por medio de la ciencia.

\subsection{La piel de un alma en un cuerpo de escritura: Catherine Pozzi}

Para Pozzi, muy influida por las teorías de Marie Jaëll ${ }^{49}$ al igual que por la metempsicosis ${ }^{50}$, el cuerpo y la mente se fusionan no pudiendo ser separados. Vemos una vez más hasta qué punto Catherine Pozzi fue una mujer adelantada a su tiempo. A lo largo de los siglos, el cuerpo y la mente han sido considerados de forma separada. Pozzi que, recibió una educación religiosa tal y como aparece tanto en su diario como en Agnès, estableció en dicha obra una división tripartita del ser humano (Alma-Cuerpo-Espíritu) ${ }^{51}$. En este sentido, el personaje de Agnès (de marcado carácter autobiográfico en el que la personalidad de Catherine Pozzi aparece de la mano de la protagonista Agnès), refleja su propia concepción de la vida. Sin embargo, y teniendo en cuenta que Catherine Pozzi empezó a redactarlo en 1922, su concepción metafísica de la existencia no estaba todavía completamente formada tal y como se demuestra en el primer ejemplo:

Voici comment je me bâtis: (Pozzi 2002: 28)

CORPS

ÂME

Vêtement parfait
Espérance

\section{ESPRIT}

Latin, grec, allemand, anglais, italien, espagnol

48. La escritora pone en duda incluso la existencia de un Paraíso.

49. Fue su profesora de piano. Desde 1895, Catherine Pozzi acudía regularmente a las clases de piano impartidas por Marie Jaëll quien desarrolló un curioso método para aprender a tocar el piano consistente en un entrenamiento de la mano. Se trataba de escuchar los colores y tocar los sonidos $(C f$. Lawrence 1988: 64.). Publicó varios tratados en los que intentaba demostrar que cuerpo y espíritu son una misma cosa. Marie Jaëll, La Musique et la psychophysiologie (1896), Le mécanisme du toucher (1897), L'intelligence et le rythme dans les mouvements artistiques (1904), Les rythmes du regard et la dissociation des doigts (1906).

50. Creencia en la transmigración del alma de un cuerpo a otro.

51. División recogida en la Primera epístola del Apóstol San Pablo a los Tesalonicenses: «Y el mismo Dios de paz os santifique por completo, y a todo vuestro ser, espíritu, alma y cuerpo, sea guardado irreprensible para la venida de nuestro Señor Jesucristo» (5:23). 


$\begin{array}{lll}\text { Musique } & \text { Hardiesse } & \text { Histoire des doctrines } \\ \text { Dessin } & \text { Persévérance } & \text { Savoir choisir } \\ \text { Santé } & \text { Sincérité absolue } & \text { Se former une foi }\end{array}$

Esta primera división de Agnès nos muestra a una joven todavía llena de esperanza y sometida a las reglas sociales de buena conducta propias de una mujer de su edad. Años más tarde, la enfermedad y su relación con Valéry la llevaron a modificar la concepción del personaje:

Comparer avec l'état actuel: (Pozzi 2002: 29)

CORPS

Robes quelconques.

Musique médiocre.

Dessin nul.

Trop sensible aux changements.
ÂME

Tendance au désespoir.

Hardiesse théorique, inopérante.

Se laisse battre par les difficultés.

Capable de mentir par fatigue ou pour plaire.
ESPRIT

Allemand, anglais.

Nomenclatures...

Ne sait pas où sont les belles choses.

Du mysticisme à la négation.

Esta segunda división nos muestra a una mujer que, en cierta medida, ha perdido el entusiasmo de los primeros años. La enfermedad ha hincado profundamente sus dientes en la piel de un cuerpo femenino que progresivamente pierde vigor. La negación de la vida misma y la reclusión son el estado de su alma reflejados en la escritura. Observamos cómo en la primera división establece una separación entre cuerpo, alma y espíritu en la formación de la joven Agnès que se prepara para encontrar a un hipotético ser amado. Es lo que denomina: «un devis d'architecte» (Pozzi 2002: 28). La construcción de Agnès como personaje, como desdoblamiento de la propia escritora se lleva a cabo mientras va escribiendo el cuento. Con el fin de ver la evolución que se produce en sí misma comparando los dos recuadros establecidos, Agnès afirma que: «Je vais épingler ces deux papiers dans ma chambre, et je marquerai les progrès qui me feront passer du tableau 1 au tableau 2» (Pozzi 2002: 30). Pero más allá de anotar sus propios progresos quiere compararlos con los del ser amado, una vez hallado.

Je pourrais exposer en face une autre page, avec vos Corps âme Esprit à vous ?

Je ne les connais pas... Si, je les connais, puisqu'ils sont ce que je désire ! -Et qu'estce que je désire ? (Pozzi 2002: 30). 
Sin lugar a dudas, entre el cuadro 1 y el cuadro 2 , se ha producido una evolución en el pensamiento de Catherine Pozzi. Es significativo resaltar cómo pasa de la necesidad por afianzarse en la formación de su propia fe al abandono de un cierto misticismo hasta llegar a la negación ${ }^{52}$ del mismo. El libro que se escribe, el personaje (Agnès) y la autora (Catherine Pozzi) forman un todo inseparable como la piel del alma. Agnès es personaje, desdoblamiento de la propia escritora, narradora heterodiégética en el interior de la novela. Pero Agnès es sobre todo el libro que se escribe en constante construcción, evolucionando al mismo tiempo que el yo femenino de la autora. El proyecto de fusión entre alma y cuerpo culminará de forma especial en De libertate, adoptando el título de Le corps de l'âme en 1930. La escritura se convertirá en un refugio necesario y vital para huir de la soledad. Para Philippe Lejeune, la joven Catherine, que ya había esbozado su autorretrato cuando tenía 14 años, es una mujer llena de energía, de proyectos pero al mismo tiempo una joven que se siente terriblemente sola: «J'ai pris son autoportrait physique, une page où elle définit son projet spirituel. Une page où elle développe le thème: "La jeune fille est un être seul" ${ }^{53}$ » (Lejeune 1993: 80). Para huir de esa soledad, la joven había comenzado a mantener un diario, un desdoblamiento de su alma, un yo más allá de lo vivido, su propio yo expresado en palabras, un «moï» (Pozzi 1987: 311) escribió Pozzi, irónicamente.

52. Catherine Pozzi nunca abandonara totalmente la idea de unirse en el más allá con el ser amado. En este sentido, hacemos alusión a la relación mantenida con André Fernet hasta la muerte de éste durante la guerra en junio de 1916. El primero de enero de ese mismo año, Catherine Pozzi escribió lo siguiente en su diario: «Ma vie, mon esprit,

Je suis la même chose que vous pour l'éternité. A travers vous, je vais vers Dieu. A cause de vous, j'exige de moi ma difficile réalité.

Nous serons mêlés parce qu'il le faut, dans un soleil qui n'est point encore, et que nous aidons à créer par la peine infinie et la volonté de notre amour qui ne se connaît pas, et pourtant trouve» (Pozzi 1987: 89). André Fernet todavía estaba en vida. Tras su desaparición y hasta su propio final, Catherine Pozzi escribió todos los primeros de año estas frases que iba modificando como homenaje a su amigo. Así, el año de su muerte para celebrar el primer día del año escribió: «Ma vie passée, mon cher esprit, je vous suis dans l'éternité. Comme vous avez tenté de la former, l'immobile image, le vous-même en qui viendrait Dieu, je la forme comme je peux. A travers vous, je vais vers lui, à cause de vous, j'exige de moi ma difficile réalité. Nous serons réunis dans l'univers qui n'est pas encore, et que nous aidons à créer par la peine infini et la volonté de l'amour qui ne connaît pas, qui connaîtra, qui trouve. Amen» (Pozzi 1987: 637).

53. En mayo de 1899, Catherine Pozzi escribió en su diario lo siguiente: «En écrivant ces pages, je ne voudrais pour rien au monde qu'elles fussent profanées par un regard indifférent, mais je voudrais qu'elles restent. Qu'elles restent, non pas comme un exemple de style -oh loin de moi cette idée ! je ne travaille pas ces lignes, j'écris sans chercher ce qui me vient du cœur-mais comme un intéressant document psychologique sur ce que pouvait être l'état d'âme d'une petite fille [...] je veux dire aux indifférents combien un enfant peut souffrir, combien une jeune fille peut être seule » (Lejeune 2006: 370). 
El diario le permitió verse reflejada en un espejo: «comme un miroir qui restituera une image globale de ce corps déchiré, de cet esprit émietté par la vie et par le temps» (Didier 1991: 112).

Su proyecto de fusión entre cuerpo y alma sobrepasa la escritura misma de sus obras. Catherine Pozzi lo aplicará incluso a su propia forma de relacionarse con el mundo, y por tanto con los hombres. La escritora intenta demostrar: «comment le corps de l'âme engagé dans l'amour altère l'amour, ou le déguise. Mon amour n'était plus altérable. Son amour [celui de Valéry] a été vaincu par l'hérédité» (Pozzi 1987: 447). En 1931, inspirándose en un cuento de Perrault Peau d'âne, y tras hojear un antiguo texto egipcio, adapta y adopta la imagen de la piel como vehículo del alma tras la muerte, y su ensayo filosófico pasa a denominarse Peau d'âme. Como afirma Lawrence Joseph: «En décidant finalement d'intituler son livre Peau d'âme, elle emploie un symbole qui unit dans un syncrétisme audacieux des notions dérivées à la fois de la science moderne, de la religion des pharaons et des Contes de Perrault» (Joseph 1988: 298). La idea de llamar a su ensayo Peau d'âme le parece cercana a la idea que concibió en sus inicios de $\mathrm{De} \mathrm{Li}$ bertate con el concepto de «Zaïmph» ${ }^{54}$, como metáfora del cuerpo recubierto por la piel del alma. En su constante interés por explicar cómo los seres humanos son capaces de sentir, tal y como lo demuestra su ensayo filosófico, Catherine Pozzi aplica a su ya avanzada forma de concebir la existencia determinados principios de la mecánica ondulatoria como la célebre hipótesis de Louis Victor de Broglie ${ }^{55}$. En su afán por unir «le corps et l'âme», afirma que lo que permite aunar ambas parte es el movimiento. Tiene que producirse primero una sensación. Pero esa sensación necesita, nos dice Pozzi, dos espacios:

54. Pozzi defiende la idea del alma material hecha de substancias del universo y determinada por leyes. La llamará Zaïmph basándose en la vela de la diosa Tanit de la obra de Flaubert Salammbô.

55. Recibió el Premio Nobel de Física en 1929 por su teoría de la dualidad onda-partícula que había desarrollado en su tesis doctoral publicada en 1924, Recherches sur la théorie des quanta, Paris, Masson et Cie. Para Catherine Pozzi la teoría de las ondas de Broglie -conocida en francés con el nombre de «Onde de phase ou Onde» y en alemán como «Materienwelle» (término que también utiliza la escritora) permitía una imbricación entre las partículas y las ondas, es decir entre lo ponderable y lo imponderable: «L'Onde de B. joue un rôle aussi capitale - c'est elle le pont cherché entre le pondérable et l'impodérable» (Pozzi 1935: 208). Asimismo, para la autora de Peau d'âme: «Les mouvements non physiques -ondes de Broglie - qui sont associés à ces pondérables, sont les objets de la perception qualitative. Ce sont eux qui pénètrent la conscience [...] L'onde de Broglie, [ou onde de phase], qui n'a pas de masse, est l'introductrice dans la conscience du mouvement pondérable associé. [...] il faut un récepteur pour le mouvement non énergétique associé. Ce récepteur et le JE» (Pozzi 1935: 209). 
Il y aurait l'espace de la sensation brute (dzing! aïe! oh!).

Et l'espace de la magie (ré bémol, rose, salé).

Non seulement ces espaces existent en moi (les chercheurs les appellent «corps» et «conscience» tout en essayant fortement de réduire au premier le deuxième) -mais ils existent au départ du signe (Pozzi 1935: 174).

En este sentido para Catherine Pozzi: «le lieu de départ est l'excitant» (Pozzi 1935: 113). Y para la escritora: «l'excitant est du grain ou du morceau d'énergie» (Pozzi 1935: 113). Por lo tanto, para sentir, tiene que haber una sensación producida por una descarga de energía, que posibilita por medio del movimiento, pasar de la materia al alma, uniendo de forma irremediable «corps» $\mathrm{y}$ «conscience»: «Ils sont inextricablement imbriqués» (Pozzi 1935: 174) porque «Peau d'âme» permite «[...] la rencontre grossière de JE et du monde extérieur» (Pozzi 1935: 126). Y de ese encuentro entre el Yo y el mundo exterior se forjan dos espacios, en eso radica lo novedoso de su teoría:

Il faut observer longtemps et ne jamais oublier ceci: les psychologues ou savants qui se sont occupés des sensations ont toujours, - il n'y a pas une exception, une seule, - admis que c'était l'excitant reconnu hors du vivant, pur signe inqualifié, le rond - qui devenait devant le vivant qualifié, chantant.

Pas un de ces chercheurs n'a fait l'hypothèse qu'il pouvait y avoir deux sortes d'excitants pour deux sortes d'émotion sensuelle absolument différentes. Pas un ne s'est dit que le rond qui cause la résonance sourde et aveugle type nerf de grenouille, n'était pas le - est-ce rond ? - qui causait la musique, le parfum, la couleur. Pas un n'a imaginé qu'à deux émotions du corps, correspondaient peut-être deux espaces extérieurs (Pozzi 1935: 175).

Sin lugar a dudas, Catherine Pozzi se adelantó a su tiempo, no tanto por su explicación metafísica del ser pensante basada en la física cuántica de las ondas ondulatorias sino por el afán en demostrar que el alma y el cuerpo no se pueden separar. La escritora se apartó de la concepción filosófica heredada por el pensamiento tradicional y que Descartes llevó a su máxima expresión. Anne Deneys-Tuney pone de manifiesto que afirmando la mutua exterioridad del alma y del cuerpo, Descartes se refiere a la repugnancia que existe entre los movimientos del cuerpo y la voluntad del alma (1992: 31-32). En la teoría de las emociones ${ }^{56}$, basada en la Neurobiología

56. Para un estudio pormenorizado de dicha teoría en relación con el racionalismo cartesiano, véase el artículo de Jesús Camarero: «Le rationalisme français et la théorie des émotions», Çédille 6, abril 2010: $52-72$ 
moderna, Antonio Damasio, prestigioso investigador en neurofisiología y autor de El error de Descartes ${ }^{57}$, nos proporciona determinadas claves científicas que demuestran la interacción entre el cuerpo y el cerebro. El error de Descartes, apunta el autor, fue precisamente separar la mente del cuerpo:

Y puesto que sabemos que Descartes imaginó que el pensar es una actividad muy separada del cuerpo, celebra la separación de la mente, la «cosa pensante» (res cogitans), del cuerpo no pensante, el que tiene extensión y partes mecánicas (res extensa) (Damasio 1994: 284).

No podemos saber a ciencia cierta si Catherine Pozzi se hubiera sumado a las teorías modernas sobre la fusión del 'cuerpomente', pero sí podemos afirmar que intentó demostrar su fusión por medio de los estudios y las herramientas que se hallaban a su alcance, y que a lo largo de toda su vida, intentó encontrar un ser con el que poder compartir su cuerpo y su mente. En cualquier caso, al igual que hiciera la princesa Elisabeth en su correspondencia ${ }^{58}$ con Descartes, en la correspondencia mantenida con Paul Valéry, Catherine Pozzi intentó encontrar una respuesta a ese conflicto. Tras su relación con Valéry en el que había creído encontrar su alma gemela: «L'amour, ce sera donc de rencontrer à l'état séparé la perfection de moimême? [...] Quelle perplexité pour que vous me plaisiez, il faut que vous soyez moi. Un autre peut-il être moi? S'il n'est pas moi tout est manqué» (Pozzi 2002: 30), intentó mantener sus principios hasta el final de su relación con Valéry. Adelantándose a la ruptura que ella misma propició, le escribió una carta el 25 de febrero de 1923 en la que afirmaba: «Tu m’as trompée, tu m’as trompée. Si tu ne me dédiais que ton esprit, il ne fallait pas vouloir mon corps. Le dieu ne m’a pas scindée en deux ; il m'a faite une seule chose» (Joseph 2006: 530). Con cierto resentimiento hacia él pero sobre todo hacia sí misma, escribió en su diario el 30 de

57. Damasio, Antonio (1994): Barcelona, Crítica. El Doctor Alexis Carrel, premio Nobel de Medicina en 1912, también mencionó textualmente en su ensayo sobre el hombre, L’homme, cet inconnu, el error de Descartes: «En somme, le corps et l'âme sont des vues prises du même objet à l'aide de méthodes différentes, des abstractions faites par notre esprit d'un être unique. L'antithèse de la matière et de l'esprit n'est que l'opposition de deux ordres de techniques. L'erreur de Descartes a été de croire à la réalité de ces abstractions et de regarder le physique et le moral comme hétérogènes. Ce dualisme a pesé lourdement sur toute l'histoire de la connaissance de l'homme. Il a créé le faux problème de l'âme et du corps» (Carrel 1937: 137-138).

58. La correspondencia mantenida entre ambos propicio en cierta medida la redacción del tratado Les Passions de l'âme (1649). Elisabeth quería que el filósofo le proporcionara una explicación que le permitiera comprender: «comment l'âme de l'homme peut déterminer les esprits du corps, pour faire des actions volontaires (n'étant qu'une substance pensante) (16 mais 1643)» (Haroche-Bouzinac 1995: 113). 
abril de 1923: «J'ai vu tout l'univers de cette tête désespérée, et pour voir, j’ai payé de mon corps» (Pozzi 1987: 262).

Marcelle Sauvageot también describió cómo él se fue progresivamente alejando de ella eligiendo la vida mundana, eligiendo la mentira frente a la sinceridad y el amor sin condiciones que ella le brindaba:

Mais, un jour, je sentis que Bébé n'était plus. [...] il était entré dans un «milieu » et ne comprenait plus l'homme qui se tenait à l'écart. Pour peu qu'on l'excitât, il aurait crié «taïaut»; et sa doctrine, fixe désormais, était de vivre médiocre pour être heureux. Il ne voulait plus me suivre. [...] On ne se sépare pas de son double en quelques instants parce qu'il a brusquement disparu. On poursuit son image, son souvenir (Sauvageot 2005: 51-52).

Y como Catherine Pozzi en Agnès, yendo en busca del amor, en busca de su otro yo como reflejo de la fusión de dos almas en el peregrinar de la vida, el dolor narrado por Marcelle Sauvageot se ve confrontado a la realidad de un destino. La pérdida no tanto del ser real sino la pérdida del ser imaginado, es decir fantaseado, construido.

Pero llegado el momento de la despedida, sólo queda esperar ya que el silencio y la distancia preservan la relación que existió, y Marcelle Sauvageot demostró una vez más que quería ser amada por encima de todas las cosas, y si ese deseo no se podía cumplir entonces:

Laissez-moi: vous ne pouvez plus être avec moi. Laissez-moi souffrir, laissez-moi guérir, laissez-moi seule. Ne croyez pas que m'offrir l'amitié pour remplacer l'amour puisse m'être un baume ; c'en serait peut-être un quand je n'aurais plus mal. Mais j'ai mal ; et, quand j'ai mal je m'éloigne sans retourner la tête. Ne me demandez pas de vous regardez par-dessus l'épaule et ne m'accompagnez pas de loin. Laissez-moi (Sauvageot 2005: 66).

Como si de una plegaria dirigida a esa voz que nunca la escuchará, como si de un profundo lamento hacia un yo ausente pero tan presente en sus palabras se tratase, el dolor por la pérdida de una esperanza de vida, es para Marcelle Sauvageot un grito de liberación más allá del miedo a la muerte.

Para ambas mujeres, la sinceridad de sus sentimientos las llevó a vivir una vida que se alejaba de las normas sociales preestablecidas. Si ambas intentaron encontrar un sentido a su existencia por medio de la razón, para estas dos escritoras, la escritura fue la fusión (tan ansiada por Pozzi) entre la mente y el cuerpo. Así lo expresaba Catherine Pozzi en su diario: «Bel Gazou? C'est la fille à Jean-Jacques 
Rousseau. [...] Elle a découvert qu'on n'écrivait pas avec les yeux (comme ces écrivains croient) mais avec tout son corps. Je suis la seule à le savoir. Ah, si je n'étais pas attachée au secret du monde !» (Pozzi 1987: 656) Razón y emoción tampoco podían escindirse. ¿Cómo separar el cuerpo de la mente? ¿Cómo supeditar las emociones a la razón? Ellas lo intentaron, quizá no lo consiguieran pero lucharon por ello hasta su último aliento. Fusionando la mente y el cuerpo tal vez encontrarían una manera de huir de la soledad de los distintos sanatorios, de una enfermedad que las apartaba de los otros, de la soledad de un amor desdichado, en definitiva de la soledad de ser y vivir en sí mismas. Si sus cuerpos abrazaran sus almas, o sus almas tocaran sus cuerpos como la mano escribiente roza el papel, como el alma de unos dedos sosteniendo la pluma, quizá conseguirían escapar de la soledad del ser recluido.

El tren las llevaba irremediablemente hacia su nueva morada. Su incesante traqueteo les recordaba que más allá de las palabras prometidas se encontraba el silencio, la soledad del camino hacia el olvido. ¿Acaso no habían hecho el camino en sentido contrario a lo moralmente preestablecido, es decir yendo de ellas a ellos? Escribe Pozzi: «Je viens puisque vous ne venez pas» (Joseph 1988: 200) ¿Y de él al sanatorio? Escribe Sauvageot: «J'avais quitté un fragile bonheur pour retourner dans ce sanatorium» (Sauvageot 2005: 7). ¿Acaso no habían sido amadas? Pregunta que quedará en el aire, tal vez el tiempo de nuevo les dé la razón. Y como escribió Valéry en sus cuadernos al saber que Catherine Pozzi había fallecido: «Non soc osa sentire. E molto di tutto. Mirammento che il primo scomparso doreva significarsi al otro» ${ }^{59}$.

\section{Conclusión}

Catherine Pozzi y Marcelle Sauvageot no se resignaron y lucharon hasta el final, fieles a sus principios, porque en definitiva la piel recubre el alma, y el ser es ser escribiente si siente como su cuerpo se deja recorrer por el impulso de la escritura. En la soledad de su enfermedad cuando el dolor se hacía tan intenso que sólo consiguía decir: «J'ai mal...à $\mathrm{moi}^{60}{ }^{6}$ (Pozzi 1987: 342), la escritura fue para

59. Escrito por Paul Valéry en sus Cuadernos tras la muerte de Catherine Pozzi (Joseph 1988: 322).

60. Tras esa expresión desesperada se esconde nuevamente toda una reflexión sobre su forma de concebir el Alma y el Cuerpo: «Cette forme bizarre m'ouvre d'un coup quelque porte de l'esprit. Je n'attendais pas de dire cela, au lieu de: «J'ai mal au dos» ou «au bras» ou «à la poitrine»..., ce «moi» sort, nommé par la chair même que je ne pensais pas, paraît comme un voleur caché» (Pozzi 1987: 342). 
Catherine Pozzi el impulso vital que la ayudó a olvidar el dolor de su propio cuerpo: «Quand je suis malheureuse de chair et de sang [...], je prends un crayon, et je disparais dans ma tête » (Pozzi 1987: 619). La escritura le proporcionó un espacio propio donde refugiarse y escapar de un mundo y una enfermedad cada vez más insoportables: «J'écris pour ne pas mourir de solitude» (Pozzi 1987: 117). El ritmo del tren marcó las primeras palabras escritas de Marcelle Sauvageot mientras ambas se adentraban en la soledad de un mismo destino. Ese élan, ese impulso escritural cuyo ritmo se asemeja al respirar, se une con el movimiento de la mano que sostiene el lápiz para conformar el aliento de vida de dos mujeres, dos escritoras que quisieron ser aquello que no fueron: un mar abierto en el desierto de la existencia, una lágrima caída en la finitud del cuerpo. Dos mujeres que por encima de todo amaron y fueron amadas, dos voces que se escribieron en el devenir del tiempo, dos escritoras que relataron una herida abierta en el ancho mar de la vida, una palabra lanzada sobre un papel mojado por la tinta de sus cuerpos, un libro que será la obra de sus vidas porque, más allá de su soledad, fueron y serán dos mujeres unidas por un mismo destino: la escritura en el propio devenir del ser yomujer-escribiente, escritora.

\section{Bibliografía}

ALBISTUR, M. y ARMOGATHE, D. (1977). Histoire du féminisme français. París: Des femmes.

AUBAUD, C. (1993). Lire les Femmes de Lettres. París: Dunod.

BROGLIE, L.V. de (1924). Recherches sur la théorie des quanta. París: Masson et Cie.

CAMARERO, J. (2010). «Le rationalisme français et la théorie des émotions». Cédille 6: 52-72.

CANNONE, B. (2000). L'écriture du désir. París: Calman-Lévy.

CARREL, A. (1937). L'homme, cet inconnu. París: Plon.

DAMASIO, A. (1994). El error de Descartes. Barcelona: Crítica.

DENEYS-TUNES, A. (1992). Écritures du corps. De Descartes à Laclos. París: PUF. DIAZ, B. y SIESS, J. (dir.) (2006). L'épistolaire au féminin. Correspondances de femmes $X V I I I^{e}-X X^{\mathrm{e}}$ siècle. Caen: PUC.

DIDIER, B. (1976). Le journal intime. París: PUF, 1991.

DIDIER, B. (1981). L'écriture-femme. París: PUF, 1991.

FERLIN, P. (1995). Femmes d'encrier. París: Christian de Bartillat.

FREUD, S. (1990). L'homme aux loups. A partir de l'histoire d'une névrose infantile. París: PUF. 
GERHARD, U. (2004). «Concepts et controverses» en Le siècle des féminismes. (Dirs. E. Gubin, C. Jacques, F. Rochefort, B. Studer, F. Thébaud, M. Zancarini-Fournel). París: l'Atelier: 47-63.

GOLDMISCHT, E. C. y WINN, C. H. (2005). Lettres de femmes: textes inédits et oubliés du XVI ${ }^{e}$ au XVIII ${ }^{e}$. París: Champion.

GRASSI, M. C. (1998). Lire l'épistolaire. París: Dunod.

GUSDORF, G. (1990). Les écritures du moi. Lignes de vie 1. París: Odile Jacob.

HAROCHE-BOUZINAC, G. (1995). L'épistolaire. París: Hachette.

JAËLL, M. (1896). La Musique et la psychophysiologie. París: Alcan F.

JAËLL, M. (1897). Le mécanisme du toucher. París: Colin.

JAËLL, M. (1904). L'intelligence et le rythme dans les mouvements artistiques. París: Alcan F.

JAËLL, M. (1906). Les rythmes du regard et la dissociation des doigts. París: Fischbacher.

JOSEPH, L. (1988). Une robe couleur du temps. París: La Différence.

JOSEPH, L. (Ed.) (2006). Catherine Pozzi-Paul Valéry. La flamme et la cendre. París: Gallimard.

JULIEN, H. M. (2000). Le roman de Karin et Paul. París: L'Harmattan.

LACAN, J. (1953). Le séminaire sur l'homme aux loups. Inédit.

LACAN, J. (1966a). «Le séminaire sur La Lettre volée» en Écrits. París: Seuil.

LACAN, J. (1966b). «Du traitement possible de la psychose» en Écrits II. París: Seuil.

LEJEUNE, P. (1993). Le moi des demoiselles. Enquête sur le journal de jeune fille. París: Seuil.

LEJEUNE, P. (2006). Le journal intime. Histoire et anthologie. París: Textuel.

LISPECTOR, C. (1998). La passion selon G.H. París: Des femmes.

MALRAUX, C. (1973). Le bruit de nos pas, IV, Voici que vient l'été. París: Grasset. PLANTÉ, C. (1989). La petite sœur de Balzac. París: Seuil.

PLANTÉ, C. (dir.) (1998). L'épistolaire, un genre féminin? París: Champion.

POZZI, C. (1935). Peau d'âme. París: Corréa.

POZZI, C. (1987). Journal 1913-1934. París: Ramsay.

POZZI, C. (2002). Agnès. París: Édition La Différence.

RIOT-SARCEY, M. (2002). Histoire du féminisme. París: La découverte.

SAUVAGEOT, M. (1939). Kommentar. Berlín: Riemerschmidt.

SAUVAGEOT, M. (2004). Déjame. Barcelona: RBA Libros.

SAUVAGEOT, M. (2004). Deixa'm. Barcelona: RBA Libros.

SAUVAGEOT, M. (2004). Laissez-moi. París, Des femmes.

SAUVAGEOT, M. (2005). Laissez-moi. París: Édition Grand caractère.

SAUVAGEOT, M. (2005). Lasciami sola. Milán: Guanda. 
STUDER, B. (2004). «Introduction. Féminisme et histoire» en Le siècle des féminismes (dirs. E. Gubin, C. Jacques, F. Rochefort, B. Studer, F. Thébaud, M. Zancarini-Fournel). París: 1'Atelier: 22-25.

WILWERTH, E. (1987). Visages de la littérature féminine. Bruselas: Mardaga. 